\title{
PENDAMPINGAN PEMBUATAN BLOG SEBAGAI MEDIA KAMPANYE SOSIAL PENYALAHGUNAAN ZAT ADIKTIF PADA BKR KELURAHAN KRATONAN, KOTA SURAKARTA
}

\author{
A. Anditha Sari ${ }^{1}$
}

\begin{abstract}
Abstrak: Pertumbuhan penggunaan Narkoba tidak hanya di kota besar tetapi hampir merata di kawasan kabupaten hingga pedesaan. Melihat kondisi ini, tidak hanya pemerintah yang berperan untuk melakukan penanganan tetapi juga seluruh lapisan masyarakat harus peduli terhadap kondisi di sekitarnya. Motivasi orang tua mendampingi anak-anaknya dengan memberikan pengertian dan pengetahuan, motivasi bagi guru di sekolah melakukan pendekatan kepada siswa didik agar tidak kehilangan jati diri yang akhirnya mudah terjerumus, dan motivasi warga di lingkungan sekitar ikut memberikan perhatian antar warga sehingga situasi dan kondisi di lingkungan tetap kondusif. Kota Surakarta berdasarkan laporan BNK sebagai kota rawan penyalahgunaan tertinggi di Jawa Tengah. Potensi ancaman didukung dengan keadaan demografis yang semakin padat. Salah satu wilayah yang padat penduduk adalah Kelurahan Kratonan. Sadar akan ancaman tersebut Kelurahan Kratonan telah memiliki sebuah wadah bagi keluarga dan remaja yaitu Kelompok BKR. Kegiatan BKR yaitu pendampingan berupa penyuluhan seks bebas dan penyalahgunaan Narkoba melalui teman sebaya. BKR Anggur aktif dalam berkegiatan, sehingga penting untuk menyediakan media interaktif antara pengurus dengan anggota, salah satunya melalui blog. Melalui pelatihan pembuatan blog target luaran yang dicapai adalah Pengurus memiliki media interaktif untuk memotivasi kesadaran bahaya Narkoba. Kegiatan pelatihan ini terbagi dalam dua tahap yaitu (1) Penyuluhan bahaya Narkoba oleh BNK Sukoharjo; (2) Penjelasan dan simulasi pembuatan blog.
\end{abstract}

Kata Kunci: Blog, Kampanye Sosial, Narkoba.

\section{The Assistance Creating A Blog as A Social Media Campaign Drug Abuse For BKR of District Kratonan, Surakarta City}

\begin{abstract}
Growth in the use of drugs actually not only in big cities but almost uniformly in a rural area of the district to. Seeing these conditions, not only the government whose role is to make the handling but also the whole society should be concerned about the conditions in the vicinity. motivation for parents accompany their children to provide understanding and knowledge, motivation for teachers in schools to approach educates students so as not to lose the identity that ultimately are vulnerable, and the motivation of the residents in the neighborhood to come give attention among citizens so that the situation and environmental conditions remain conducive. Surakarta is consists of five districts based on reports BNN Surakarta as the first drug abuse-prone city in Central Java. This is supported by the demographic situation is increasingly. One of overpopulated area is district Kratonan. Aware of these threats Kratonan districts have a place for families and teens that BKR Group. Activities that are often carried out this group is counseling assistance in the form of free sex and drug abuse by peers. BKR is still active in activism, so it is important to providing media interactive between board members that blog. Through training blog creation targets were achieved outcomes Board has interactive media to target audiences about drugs and the impact of its misuse for the body. This training is divided into two stages: (1) Extension dangers of drugs by BNK Sukoharjo; (2) Explanation and simulation of blog creation.
\end{abstract}

Keywords: Blog, Drugs, Social Campaigns.

\footnotetext{
${ }^{1}$ Politeknik Indonusa, Surakarta; email: andynanta@gmail.com.
} 


\section{PENDAHULUAN}

Awal tahun 2015, pemerintah melalui Presiden Joko Widodo menyebut Indonesia telah berada dalam situasi darurat Narkoba. Karenanya presiden kemudian mencanangkan Gerakan Rehabilitasi 100.000 penyalahguna Narkoba. Gerakan ini dicanangkan untuk menekan laju pertumbuhan penyalahgunaan dan peredaran gelap Narkoba di Indonesia.

Pemerintah melalui badan narkotika dan instansi terkait terus berupaya melakukan penanganan baik oleh pemerintah pusat dan daerah dalam menghadapi kondisi ancaman darurat Narkoba yang sudah di depan mata. Pertumbuhan penggunaan Narkoba nyatanya tidak hanya di kota-kota besar, tetapi hampir merata di kawasan kabupaten hingga pedesaan.

Pengguna penyalahgunaan Narkoba bisa siapa saja. Mulai dari anakanak,dewasa sampai orang tua. Hal ini bisa terjadi karena berbagai factor yang mendukung. Hal-hal yang bisa mendukung seseorang sebagai pengguna Narkoba antara lain ; factor ketidaktahuan, factor permasalahan pribadi, factor lingkungan, dan factor finansial. Seseorang yang memiliki beban hidup atau permasalahan pribadi yang cukup rumit namun kehilangan akal untuk menyelesaikan permasalahnnya cenderung melakukan pelampiasan ke halhal negatif. Ditambah dengan ketidaktahuan pengguna atas dampak bahaya Narkoba bagi tubuh jika digunakan secara sembarangan. Pengguna juga bisa termotivasi ikut menggunakan karena bujuk rayu dari orang-orang yang berada di lingkungan sekitarnya.

Melihat kondisi seperti ini, ternyata tidak hanya pemerintah yang berperan untuk melakukan penanganan tetapi juga seluruh lapisan masyarakat harus peduli terhadap kondisi di sekitarnya. Masyarakat Indonesia harus bergerak bersama-sama melakukan pencegahan dan pendampingan terutama kepada pemuda-pemuda yang akan menjadi generasi Indonesia Emas 2045 nanti. Perlu ada motivasi bagi orang tua mendampingi anak-anaknya dengan memberikan pengertian dan pengetahuan, motivasi bagi guru di sekolah untuk melakukan pendekatan kepada siswa didik agar tidak kehilangan jati diri yang akhirnya mudah terjerumus, dan motivasi warga di lingkungan sekitar untuk ikut memberikan perhatian antar warga sehingga situasi dan kondisi di lingkungan tetap kondusif.

Kota Surakarta merupakan salah satu kotamadya terdiri dari 5 kecamatan yaitu Kecamatan Banjarsari, Kecamatan Laweyan, Kecamatan Serengan, Kecamatan Jebres, dan Kecamatan Pasarkliwon. Berdasarkan laporan BNN Kota Surakarta merupakan rawan penyalahgunaan Narkoba pertama se Jawa Tengah. Pada tahun 2013 ada 70 kasus penyalahgunaan Narkoba yang ditangani di Kota Solo. Kemudian urutan berikutnya Kota Semarang dan Cilacap kemudian Purwokerto, Magelang, Tegal dan Pekalongan. Dari populasi penduduk usia produktif 23,3 juta jiwa di Jateng, sebanyak 493.533 jiwa terindikasi pengguna Narkoba. Angka prevalensi pengguna Narkoba di Jateng sebesar 2,11 persen tergolong tinggi dibandingkan dengan prevalensi nasional yang hanya 1,9 persen dari seluruh 
populasi. Kebanyakan 70 persen pengguna Narkoba berasal dari kalangan pekerja

Kondisi penyalahgunaan Narkoba dari tahun 2013-2015 terus mengalami peningkatan, oleh karenanya perlu adanya peran serta langsung masyarakat sekitar untuk mencegah hal tersebut di wilayah lingkungannya sendiri. Sebagai bentuk kepedulian perlu dilakukan komunikasi yang intensif dengan masyarakat terutama kalangan pemuda karena merupakan generasi emas 2045. Sebuah komunikasi yang membentuk pemahaman dan pencegahan akan bahaya penggunaan Narkoba bagi diri sendiri dan lingkungannya.

Sebagai bentuk mewujudkan peran serta perguruan tinggi khususnya Politeknik Indonusa Surakarta terutama dalam mengimplementasikan Tri Dharma Perguruan Tinggi, yaitu pengabdian kepada masyarakat,maka tim pengabdian masyarakat Politeknik Indonusa Surakarta merancang kegiatan "Pendampingan pembuatan blog sebagai media kampanye sosial tentang penyalahgunaan Narkoba bagi Bina Keluarga Remaja Kelurahan kratonan Kecamatan Serengan Kota Surakarta."

\section{METODE PELAKSANAAN}

Guna memecahkan permasalahan di atas maka dilakukan survey terlebih dahulu mengenai potensi anggota, proses kegiatan BKR di lingkungan, dan kondisi lingkungan keluarga sekitar.Melihat kurangnya pengetahuan pemuda di wilayah kelurahan kratonan tentang penggunaan media sosial terutama blog .Selain itu belum adanya media interaktif dalam Bina Keluarga Remaja sebagai langkah aktif pencegahan penyalahgunaan Narkoba .Melalui media blog Bina Keluarga Remaja (BKR) Anggur, pengurus BKR mampu melakukan kampanye sosial pencegahan tahap awal dari bahaya Narkoba.

Pelatihan ini juga sebagai wadah bagi warga untuk membentuk rancangan pesan-pesan komunikasi ditujukan untuk memberikan dampak kognitif dan afektif khalayak sasaran tentang Narkoba dan dampak penyalahgunaannya bagi tubuh melalui media blog. Metode pelaksanaan yang diterapkan dalam kegiatan ini meliputi berbagai pendekatan, yaitu metode ceramah, metode diskusi/FGD, dan simulasi.

Metode ceramah dipilih untuk memberikan penjelasan tentang Narkoba dan perencanaan komunikasi yang bersifat persuasif dan informatif. Metode ini memotivasi pemuda agar muncul ide-ide pesan yang menarik dan mampu mengajak orang lain ikut serta dalam mencegah penyalahgunaan Narkoba. Materi yang diberikan: 1) Pengetahuan tentang Narkoba; 2) Macam-macam Narkoba; 3) Bahaya Narkoba; 4) Contoh-contoh kasus yang terjadi akibat penyalahgunaan Narkoba; dan 5) Materi Perencanaan Komunikasi Melalui Blog.

Metode tanya jawab atau diskusi sangat penting bagi para peserta kegiatan untuk memperjelas pengetahuan tentang Narkoba. Metode ini memungkinkan pemuda menggali pengetahuan sebanyak-banyaknya tentang permasalahan-permasalahan yang muncul akibat penyalahgunaan Narkoba 
sehingga menginspirasi untuk memunculkan ide pesan yang menarik dan mampu mengajak orang lain ikut serta dalam mencegah penyalahgunaan Narkoba.

Metode simulasi ini sangat penting diberikan kepada peserta kegiatan untuk memberikan kesempatan mempraktekkan materi kegiatan perencanaan komunikasi yang diperoleh. Harapannya, peserta pelatihan akan benar-benar menguasai materi kegiatan yang diterima, mengetahui tingkat kemampuannya menerapkan kegiatan perencanaan komunikasi secara teknis dan kemudian mengidentifikasi kesulitan-kesulitan (jika masih ada) untuk kemudian dipecahkan bersama.

\section{HASIL DAN PEMBAHASAN}

Kelurahan Kratonan merupakan salah satu wilayah di Kecamatan Serengan yang berkembang kian pesat. Perkembangan ini menjadikan Kratonan memiliki permukiman yang sangat padat seperti yang terlihat dalam Tabel 1. Melihat demografi dan situasi sosial masyarakat di Kelurahan Kratonan Kecamatan Serengan, menjadikan rentan sering terjadi permasalahan sosial kemasyarakatan salah satunya penyalahgunaan Narkoba di lingkungan sekitar.

Tabel 1. Luas Wilayah, Jumlah Penduduk,dan Tingkat Kepadatan di Kecamatan Serengan Kota Surakarta Tahun 2013

\begin{tabular}{lcccccc}
\hline \multirow{2}{*}{ Kelurahan } & \multicolumn{2}{c}{ Laki-laki } & \multicolumn{2}{c}{ Perempuan } & \multicolumn{2}{c}{$\mathrm{L}+\mathrm{P}$} \\
\cline { 2 - 7 } & $\mathrm{n}$ (jiwa) & $\%$ & $\mathrm{n}$ (jiwa) & $\%$ & $\mathrm{n}$ (jiwa) & \multicolumn{1}{c}{$\%$} \\
\hline \multicolumn{1}{c}{$(1)$} & $(2)$ & $(3)$ & $(4)$ & \multicolumn{1}{c}{$(5)$} & \multicolumn{1}{c}{$(6)$} & \multicolumn{1}{c}{$(7)$} \\
\hline Joyotakan & 3.765 & 14,11 & 3.809 & 13,77 & 7.574 & 13,94 \\
\hline Danukusuman & 5.003 & 18,75 & 5.212 & 18,85 & 10.215 & 18,80 \\
\hline Serengan & 5.375 & 20,15 & 5.543 & 20,04 & 10.918 & 20,09 \\
\hline Tipes & 5.885 & 22,06 & 6.053 & 21,89 & 11.938 & 21,97 \\
\hline Kratonan & 2.706 & 10,14 & 2.872 & 10,39 & 5.578 & 10,27 \\
\hline Jayengan & 2.005 & 7,51 & 2.154 & 7,79 & 4.159 & 7,65 \\
\hline Kemlayan & 1.942 & 7,28 & 2.010 & 7,27 & 3.952 & 7,27 \\
\hline \multicolumn{1}{c}{ Jumlah } & 26.681 & 100,00 & 27.653 & 100,00 & 54.334 & 100,00 \\
\hline
\end{tabular}

Kegiatan penyuluhan bahaya penyalahgunaan Narkoba dilaksanakan pada tanggal 12 November 2016 ini diisi oleh penyuluh Narkoba BNK Kabupaten Sukoharjo. Penyuluhan menggunakan metode diskusi yang santai dengan menceritakan pengalaman salah satu rekannya mantan pengguna Narkoba. Peserta bisa secara langsung melakukan tanya jawab dengan mantan pengguna tersebut.Selain itu, Danar juga menggunakan metode mengajak peserta menyanyikan sebuah lagu bersama peserta. Hal ini 
dilakukan agar peserta lebih mudah menerima informasi yang telah diberikan dan menarik afektif peserta. Dari kegiatan penyuluhan Narkoba oleh BNK, pengelola BKR dan warga bisa mengetahui seluk beluk Narkoba. Berdasarkan penuturan salah satu mantan pengguna,warga bisa secara sadar memahami bagaimana Narkoba beredar, jenis apa saja yang biasa digunakan, dan bagaimana warga mewaspadai peredaran Narkoba di wilayahnya. Seperti yang terlihat dalam Gambar 1.

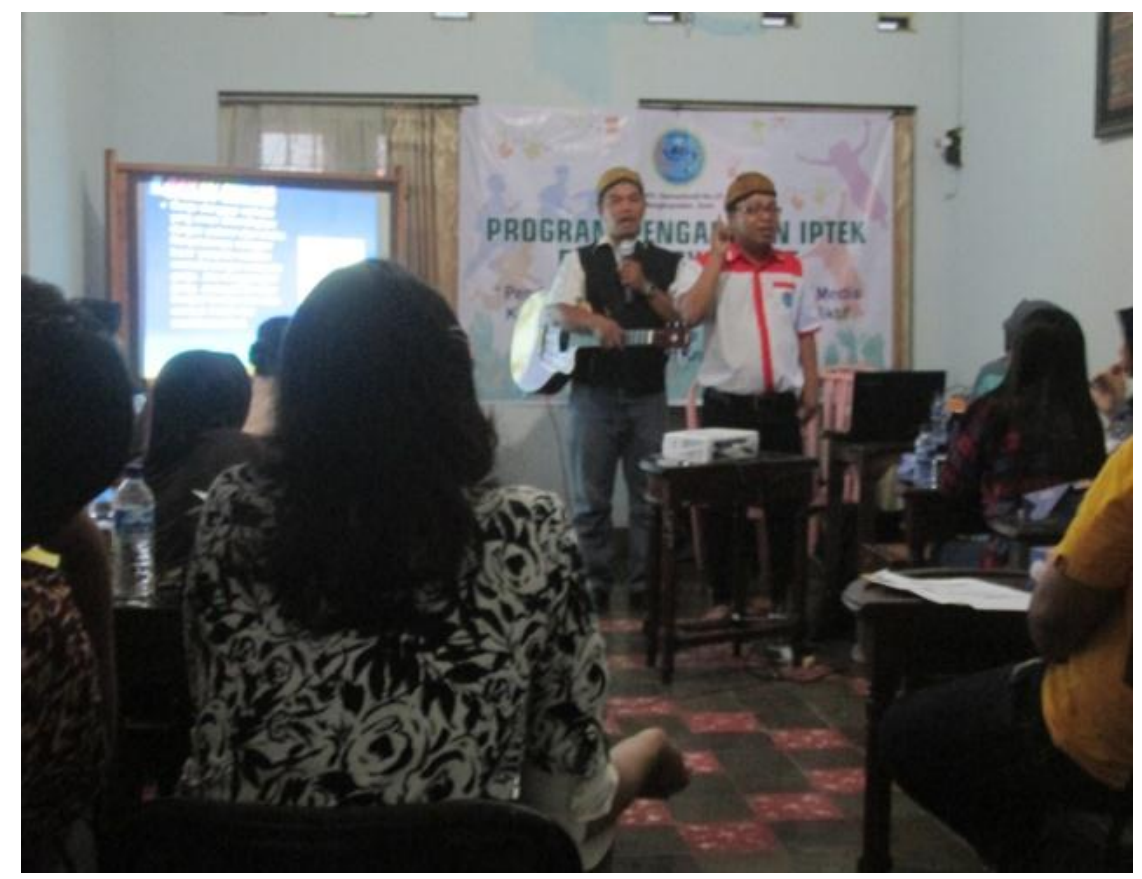

Gambar 1 Penyuluhan Narkoba oleh BNK Sukoharjo

Kegiatan selanjutnya materi mengenai blog diisi menggunakan metode presentasi mengenai pengertian blog, jenis-jenis blog, situs penyedia blog, manfaat menggunakan blog, dan cara mengelola blog agar menarik dilanjutkan dengan simulasi pembuatan blog (Gambar 2). Melalui simulasi Pengelola BKR mampu untuk membuat dan menyunting blog. Pengelola BKR juga merumuskan tema-tema apa saja yang bisa masuk dalam blog tersebut, dan menyusun kerangka tulisan (outline), mengorganisasikan, dan mengonsep tulisan secara teknis (Gambar 3). Blog yang telah dibuat (Gambar 4) mampu dilanjutkan dengan diisi dengan berbagai konten positif dan setiap kegiatan BKR di wilayahnya. Hal ini bertujuan agar diketahui oleh khalayak luas dan menjadi inspirasi bagi pengakses blog. 


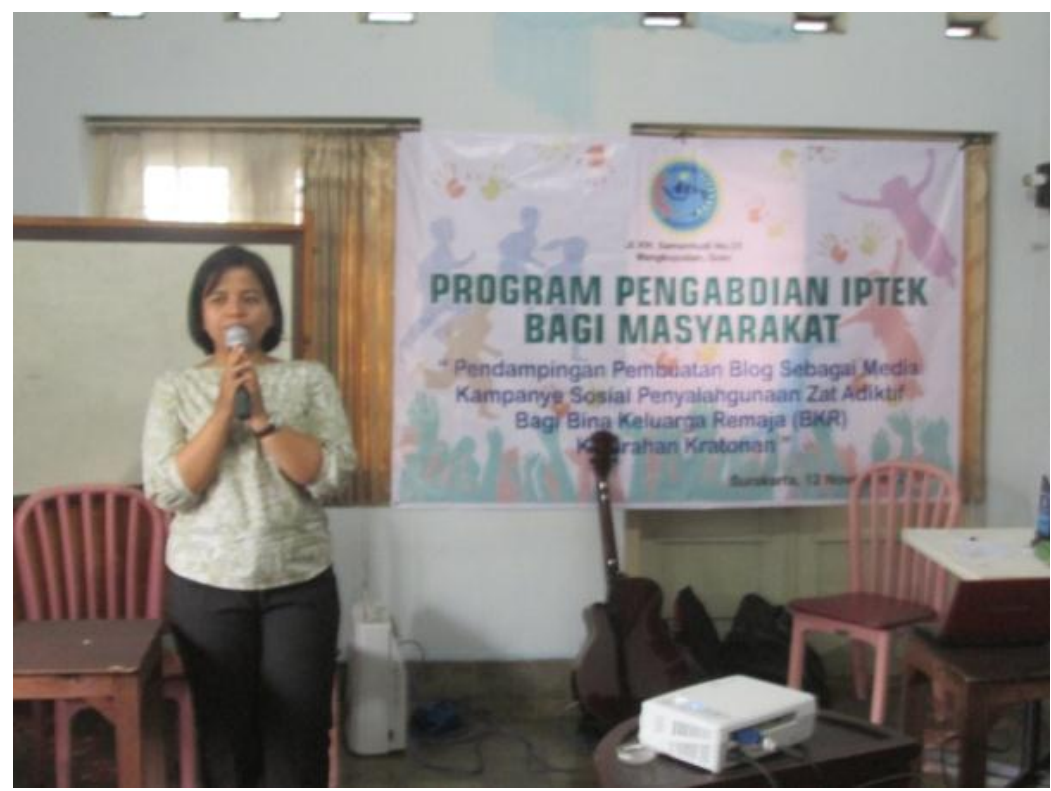

Gambar 2 Presentasi Materi Blog

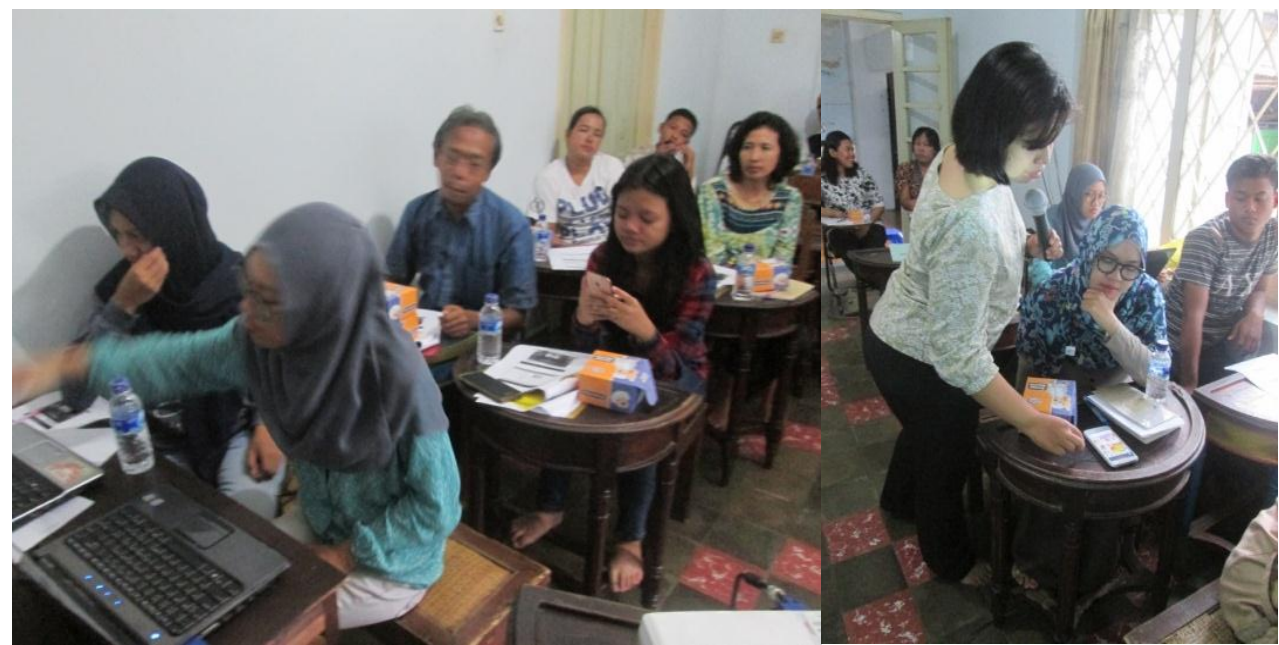

Gambar 3. Simulasi Membuat Blog: Desain Blog dan Merumuskan Konten 


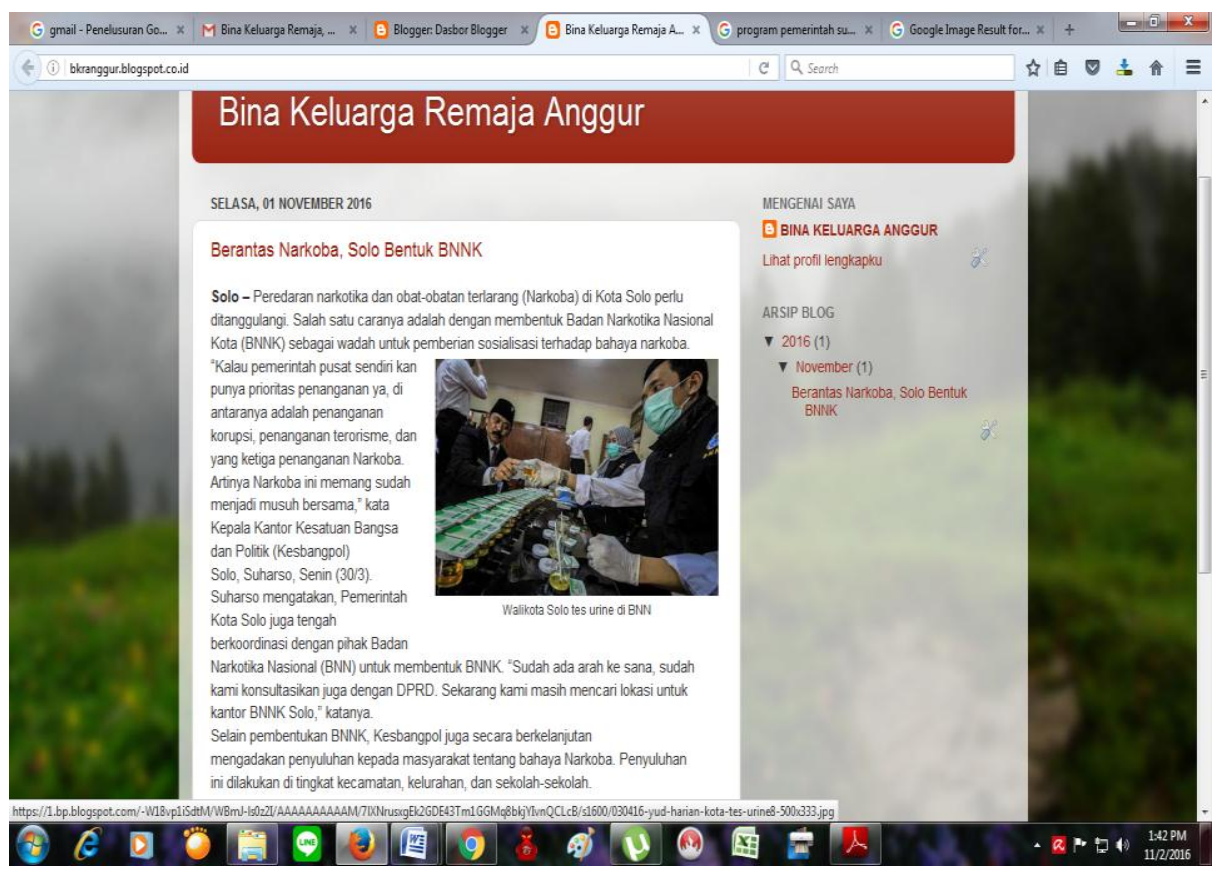

Gambar 4. Tampilan Blog BKR Anggur

\section{KESIMPULAN}

Dalam hasil kegiatan pelatihan ini masyarakat dapat menerima dengan baik karena didasari keinginan untuk memberikan motivasi kepada keluarga untuk lebih mendekatkan diri dan peduli kepada anak remaja. Melalui kegiatan pendampingan pembuatan blog sebagai media kampanye sosial penyalahgunaan Narkoba bagi bina keluarga remaja kelurahan kratonan kecamatan serengan kota surakarta diharapkan pengurus mampu merancang pesan-pesan komunikasi ditujukan untuk memberikan dampak kognitif dan afektif khalayak sasaran tentang Narkoba dan dampak penyalahgunaannya bagi tubuh melalui media blog.

Hasil dari perancangan komunikasi ditunjukan untuk membangun perubahan sikap khalayak sasaran yang ditandai dengan tindakan nyata berupa blog yang berisikan pesan-pesan persuasif dan informatif untuk mulai peduli terhadap lingkungannya dari ancaman penyalahgunaan Narkoba. Selain itu diharapkan blog yang telah dibuat mampu dilanjutkan dengan diisi konten positif dan setiap kegiatan BKR di wilayahnya. Hal ini bertujuan agar diketahui oleh khalayak luas di luar kelurahan kratonan sehingga menjadi inspirasi bagi masyarakat luas.

\section{REFERENSI}

Effendy, O. U. (2002). Dinamika komunikasi. Bandung: Rosdakarya.

Herutomo, A. (2010). Conquering web 2.0. Jakarta: Elex Media Komputindo. 

A. Anditha Sari

Gerungin, W. A. (1988). Psikologi sosial. Bandung: Eresco.

Hakim, R. (2010). Cara cerdas mengelola blog. Jakarta: Elex Media Komputindo.

Kevin, H. ( 1996). The psychology of persuation. Jakarta: Profesional Book.

Mulyana, D. (2000). Human communication-prinsip-prinsip dasar. Bandung: Rosdakarya.

Mulyana, D. (2000). Ilmu komunikasi suatu pengantar. Bandung: Rosdakarya.

Morissan. (2010). Psikologi komunikasi. Bogor: Ghalia Indonesia.

Rahmat, J. (2007). Psikologi komunikasi. Bandung: Rosdakarya.

Solomon, G., \& Schrum, L. (2011). WEB 2.0 panduan bagi para pendidik. Jakarta: Indeks.

\section{UCAPAN TERIMA KASIH}

1. Ir. Suci Purwandari, M.M. selaku Direktur Politeknik Indonusa, Surakarta.

2. Kepala Kelurahan Kratonan Kota Surakarta.

3. Danar Widanarko S,E., M.M. sebagai penyuluh Narkoba BNK Kabupaten Sukoharjo. 